\title{
Formation of an air jet by a fan installation with pneumatic disk sprayer
}

\author{
Lee Afanasiy ${ }^{1 *}$, Burkhan Utepov ${ }^{1}$, and Satniyaz Allaniyazov ${ }^{2}$ \\ ${ }^{1}$ Tashkent Institute of Irrigation and Agricultural Mechanization Engineers, Tashkent, Uzbekistan \\ ${ }^{2}$ Branch of the Tashkent State Agrarian University in Nukus, Karakalpakstan, Uzbekistan
}

\begin{abstract}
The article presents the theoretical background, in particular, the developed mathematical models describing the technological processes of air-jet formation and the influence of the wind wheel on changes in the axial velocities of the air jet, as well as the range of the air jet by a fan installation with a pneumatic disk sprayer. Theoretical studies show that the smooth variation of the axial velocity air flow fan installations and prevent the transfer of the isothermal jet of the circular cross-section of the air flow into the annular, possibly with applications on disk atomizer additional fairing and, to reduce the impact of Pavlovskogo spray on the variation of the axial velocity of the air flow and range of the fan system must be applied wind wheel with the highest energy efficiency of the air flow.
\end{abstract}

\section{Introduction}

Cotton is the main and most valuable technical crop cultivated on the territory of the Republic of Uzbekistan [1, 2].

An important element in the complex of measures for growing high yields of agricultural crops, including cotton, is the chemical protection of plants from pests, diseases, and weeds, which can significantly reduce losses and avoid reducing the quality of agricultural products. In addition, for high-quality machine cleaning, a necessary condition is the artificial removal of cotton leaves by carrying out pre-harvest defoliation [3]. As timely and quality defoliation accelerates ripening and disclosure of boxes for 10-15 days, the productivity of cotton pickers $10 \ldots 15 \%$, increased output of machine collection of raw cotton to $90 \%$, the growth of output of first-class fiber $4 \ldots 5 \%$, reduction of contamination of raw cotton in 1.5 ...2.0 times and humidity in 2...3 times [4].

Among the many known methods of treating plants with pesticides (pollination, spraying, fumigation, aerosols, etc.), the most effective in the economic, agrotechnical, and environmental aspects are spraying, through which about $75 \%$ of the work volume is performed [5-8].

Therefore, creating a high-performance sprayer that meets the requirements of lowvolume spraying of cotton is an urgent task.

*Corresponding author: magnaty_82@list.ru 
The purpose of this work is to study the process of liquid spraying by a smooth rotating disk with a coaxially-lateral air flow for the development of a working body for a serial sprayer OVH-600 for a low-volume method of spraying cotton.

\section{Methods}

Theoretical studies for calculating the main parameters of the device are carried out using the general laws of mechanics [9-13].

\section{Results and Discussion}

As you know, the parameters of wind turbines are determined using the aerodynamic characteristics, which show how the torque $\mathrm{M}$ and the coefficient of wind energy use will change [14].

Relative torque $M_{o}$ and wind energy utilization coefficient $\xi$ are determined from the following expressions [14].

The moment developed by the wind wheel:

$$
M=M_{\mathrm{o}} \pi R_{v}^{3} \rho v U / 2
$$

where: $R_{v}$ is the radius of the propeller, $\mathrm{m} ; \rho_{v}$ is air flow density, $\mathrm{kg} / \mathrm{m}^{3}, \mathrm{~kg} \mathrm{~s} / \mathrm{m}^{4} ; U$ is airflow rate, $\mathrm{m} / \mathrm{s}$.

The torque required to rotate the wheel:

$$
M=J \cdot \omega^{2}
$$

where: $J$ is moment of inertia, $\mathrm{kg} / \mathrm{m}^{2} ; \omega$ is spray gun rotation speed, $\mathrm{s}^{-1}$.

It is experimentally established that the radius of inertia of the wind wheel is approximately equal to $\rho_{x}=0.44 R_{v}$; therefore, the moment of inertia of the wind wheel is approximately [14]:

$$
J=m \rho_{x}^{2}=m\left(0.44 R_{v}\right)^{2}=0.2 m R_{v}^{2}
$$

Then the torque is:

$$
M=0.2 m R_{v}^{2} \omega^{2}
$$

Using the well-known expression of the air flow energy utilization factor [17]:

$$
\xi=\frac{2 \mathrm{M} \omega}{\pi R_{v}^{2} \rho_{v} U^{3}}
$$

Substituting the value of the torque $M$ for the formula (5) and after some simplifications, we get the dependence of the speed of rotation of the wind wheel on the speed of the airflow:

$$
\omega=2 U \sqrt[3]{\frac{\rho_{v} \xi}{m}}
$$

where: $m$ is total weight of the sprayer, $\mathrm{kg}$.

Figure 1 shows a graph of the dependence of the speed of rotation of the wind wheel on the air flow velocity $U$ at $\xi=0.593$ and $m=$ const. 
As the graph shows, the frequency of rotation of the propeller is directly proportional to the speed of the airflow, and an increase in the energy use of the air flow $\xi$ increases speed and increase the mass $\mathrm{m}$ of the propeller is affected negatively and not depend on the radius of the propeller $R_{v}$.

In practical studies, using the formula (6) and the graph mentioned above (Fig. 1), we can determine the limits of the deviation of the rotation frequency depending on the air flow velocity $U$. The aerodynamic characteristics of wind wheels depend not only on the shape of the body and its position in relation to the flow but also on the forces of viscosity that slow down air movement. These forces are characterized by the Reynolds number:

$$
R_{v}=\frac{U l}{v}=\text { const }
$$

Experimental studies have established that at Reynolds numbers exceeding 300,000, the coefficients of aerodynamic characteristics, the coefficient of lift $C_{y}$, and the drag force $C_{x}$, practically remain independent of this number. Therefore, when testing wind wheels, it is necessary to ensure that the Reynolds number exceeds a certain specified value.

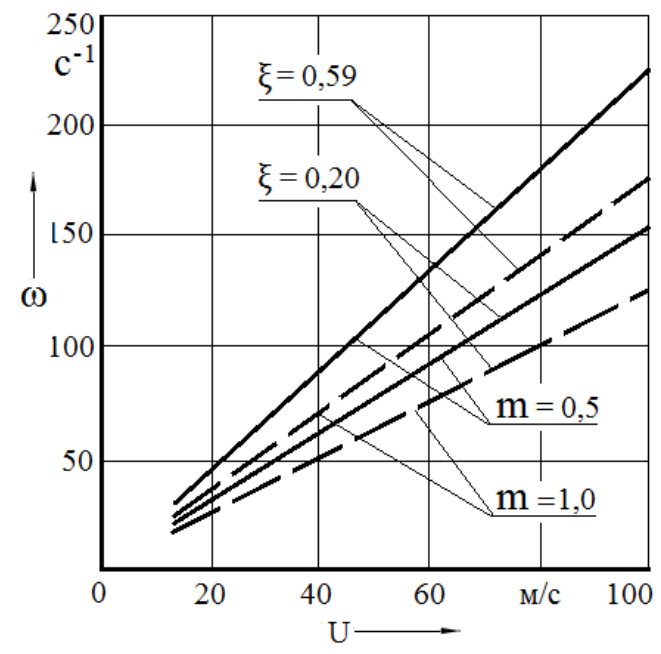

Fig. 1. The dependence of the speed of rotation $\omega$ of the wind wheel on the speed $U$ of the airflow For example, for a wind wheel blade, there should be:

$$
\frac{U B_{l}}{v}>R_{e}>300000
$$

Under normal conditions: $t=15^{\circ}, v=1.45 \cdot 10^{-5} \mathrm{~m}^{2} / \mathrm{s}$

$$
U B_{l}=4.35
$$

From the expression (8), we find the width of the wind wheel blade as a function of the airflow velocity:

$$
B_{l=\frac{4.53}{U}}
$$

With an increase in the speed $U$ of the air flow and the preservation of the values of the Reynolds number $\mathrm{R}_{\mathrm{e}}>300000$, the width of the $B_{l}$ of the wind wheel blade decreases (fig. $2)$. 


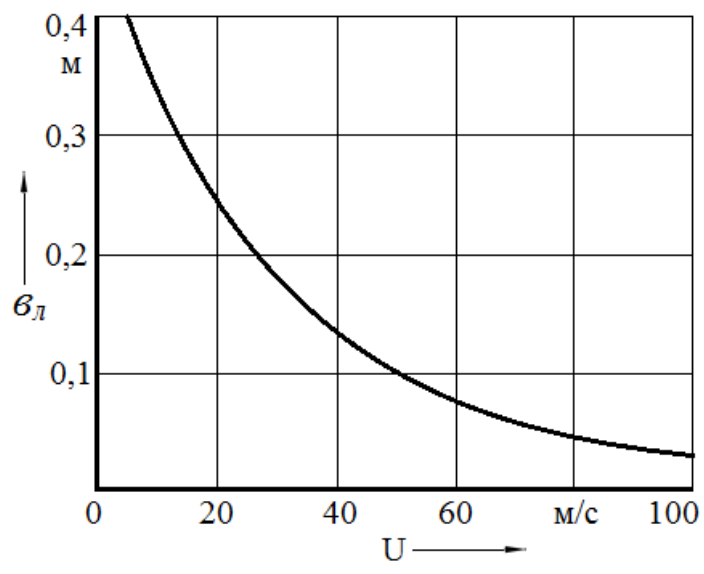

Fig. 2. Dependence of the width of the wind wheel blade on the airflow velocity

The outlet section of the nozzle of the cotton sprayer has an elongated narrow elliptical shape [15].

Consider the scheme of forming an air jet from the nozzle with the installation of a rotating spray gun with a wind wheel on the output section. In this case, the isothermal jet of the air flow takes an annular shape, i.e., a rest region is formed behind the spray with a radius $r$, where there are no mass forces, since the air flow velocity $U$ is zero (Figure 3 ).

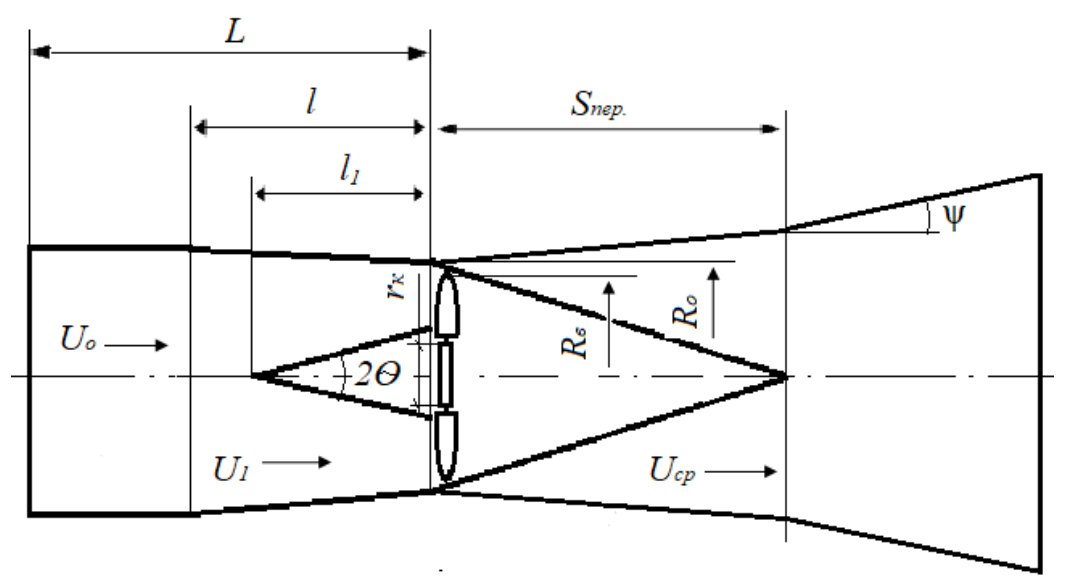

Fig. 3. Diagram of the output section of the nozzle of the pneumatic disk sprayer

The shape of the annular section depends on the angle enclosed between the jet axis and the axis of symmetry. At $\psi>30^{\circ}$, the shape of the isothermal jet has an annular shape, and at $\psi$ $<30^{\circ}$, the jet axis begins to bend towards the axis of symmetry and the jet is transformed into a jet of circular cross-section [16, 17]. Therefore, if the angle $\psi<30^{\circ}$ is observed, the isothermal shape of the circular cross-section of the existing fan sprayer will not change significantly. Therefore, for a smooth change in the axial velocities of the airflow and to preserve the circular isothermal section of the air jet, it is necessary to install a cone-shaped straightening element (fairing) with a lateral expansion angle $\Theta \leq \psi$ on the sprayer. Then, from the similarity of the triangles, we find the parameters of the cone-shaped fairing:

$$
\operatorname{tg} \theta=\frac{r_{k}}{l_{1}}
$$


where: $r_{\kappa}$ is radius of the base of the cone-shaped fairing, $\mathrm{m} ; \mathrm{l}_{1}$ is height (length) of the cone-shaped fairing, $\mathrm{m}$.

For the formation of a steady movement of the airflow, it is necessary to pass a distance equal to $2 / 3$ of the length of the nozzle:

$$
l_{1}=\frac{2}{3} L
$$

Based on this, we get:

$$
l_{1 \max }=\frac{1}{3} L
$$

Then:

$$
\operatorname{tg} \theta=\frac{3 r_{k}}{L}
$$

It follows from the expression that the maximum radius of the base of the fairing should be:

$$
r_{k \max }<\frac{L}{3} \operatorname{tg} \theta
$$

Figure 4 shows the dependence of the $\mathrm{r}_{\mathrm{k}}$ on the angle $\theta$ for a serial cotton sprayer at $L=$ 0.5 and $R_{o}=0.2 \mathrm{~m}\left(R_{o}\right.$ is the average radius of the nozzle outlet section, $\left.\mathrm{m}\right)$.

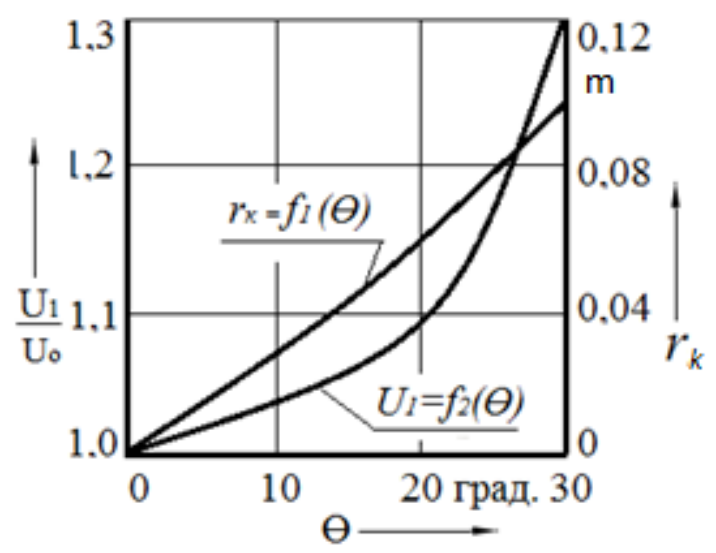

Fig. 4. Dependence of the radius of the fairing base $r_{k}$ and the change in the axial velocity $U_{l}$ of the airflow in the area of the fairing action on the angle of lateral expansion $\theta$

The graph shows that if the angle $\theta<30^{\circ}$ is observed, the maximum radius of the base of the cone-shaped fairing is equal to $r_{k \max }=0,96 \mathrm{Mu}$. Now consider the change in the axial velocity of the airflow behind the wind wheel. A stream of air comes out of the round hole, forming a jet of circular cross-section. The airflow when approaching the wind wheel in the area of the fairing, due to the difference in cross-sectional areas, has an axial velocity $U_{l}$ :

$$
U_{1}=\frac{Q_{v}}{\gamma_{z h} F_{1}}=\frac{U R_{o}^{2}}{R_{0}^{2}-r_{k}^{2}}
$$

Substituting the value of $r_{k}$ in the expression (14), we get: 


$$
U_{1}=\frac{U_{o} R_{o}^{2}}{R_{0}^{2}-\frac{L^{2}}{9} \operatorname{tg} \theta^{2}}
$$

Figure 4 shows the dependence of the velocity change $U_{l}$ on the angle $\Theta$ at $R_{o}=$ const, $L=$ const, and $U=$ const.

It is known that when passing through the area $R_{b}$ blown by the wind wheel, the airflow speed drops sharply [14-21]:

$$
U_{3}=U_{1}-U_{2}
$$

Loss of speed $U_{2}$ to the wind depends on the ratio of energy use airflow wind wheel, which is determined by the formula [14]:

$$
\xi=4\left(1-\frac{U_{2}}{U_{1}}\right)^{2} \frac{U_{2}}{U_{1}}
$$

Substituting the value $\xi$ in the expression (17) and after some transformation, we get an equation describing the nature of the change in the speed of the air $U_{3}$ behind the wind wheel:

$$
U_{3}^{3}-U_{1} U_{3}^{2}+\frac{U_{1}^{3}}{4} \xi=0
$$

Solving equation (18), we obtain the changes in the velocity $U_{3}$ of the air as a function of $\xi$ and $U_{\mathrm{o}}$ :

$$
\begin{gathered}
U_{3}=\frac{U_{o} R_{o}^{2}}{R_{o}^{2}-r_{k}^{2}}\left[\left\{\sqrt{1.5610^{-2}} \xi(\xi+2.37)-(0.125 \xi+0.037)\right\}^{\frac{1}{3}}+\right. \\
\left.+\left\{\sqrt{1.5610^{-2}} \xi(\xi+2,37)-(0.125 \xi+0,037)\right\}^{\frac{1}{3}}\right]-\frac{U_{o} R_{o}^{2}}{3\left(R_{o}^{2}-r_{k}^{2}\right)} ;
\end{gathered}
$$

With the increase of the ratio $\xi$ of energy use, air flow wind wheel $U_{3}$ increases the speed of the airstream behind the wheel, i.e., reduced loss of speed $U_{2}$ to the air flow on the wind, and $U_{3}$ is approaching $U_{0}$ (fig. 5).

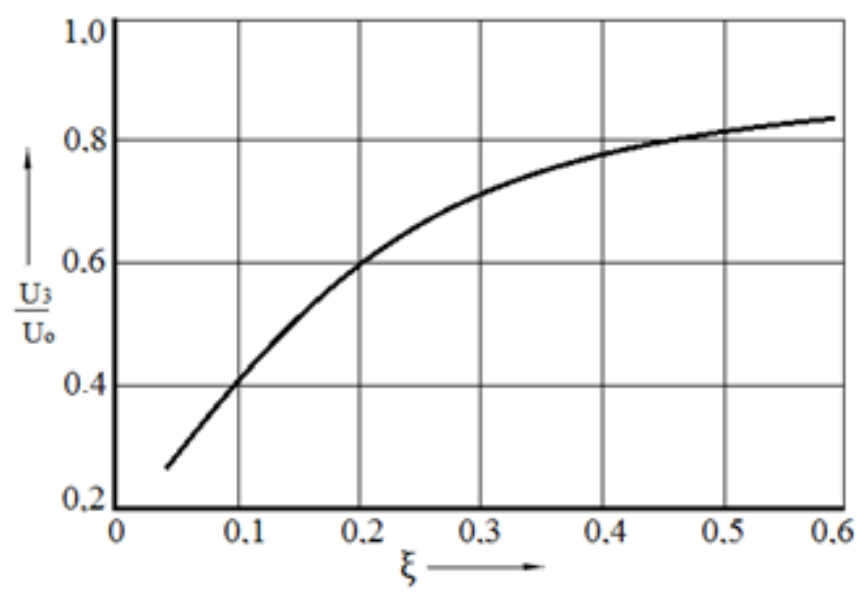

Fig. 5. Dependence of the velocity of the air jet $U_{3}$ on the wind wheel $\xi$ at $U_{0}=$ const 
Analyzing the graph of and using the values $R_{0}=0.2 \mathrm{~m}, L=0.5 \mathrm{~m}$ and $\theta=300$ in equation (19) and after some transformations get the empirical formula to determine the change of axial velocity air flow wind wheel sprayer:

$$
U_{3}=U_{0} \sqrt[3]{\xi}
$$

Thus, when installing a pneumatic disk sprayer with the highest coefficient of airflow energy use by a wind wheel, the change in the axial airflow velocities is not significant.

To determine the range of the free air jet of the cotton sprayer, depending on its initial parameters and modes: the average axial velocity $U_{c p}$ at the nozzle outlet, the average radius $R_{o}$ of the nozzle, and the air flow $Q_{b}$, we used the known aerodynamic relations for the second air flow and the power spent on creating the jet [18]:

$$
Q_{v}=U_{a v} \pi R_{0}^{2}, \quad N_{v}=\frac{Q_{o} U_{a v} \rho_{v}}{150 \gamma} .
$$

where: $Q_{o}$ is initial air flow rate, $\mathrm{m} 3 / \mathrm{sec} ; \gamma-$ is air viscosity, cst.

Determining the range of the free jet of the cotton sprayer as the distance $X_{\text {umin }}$ from the initial cross-section, the axial velocity in which is equal to the minimum permissible from the condition of effective use of the jet on the cotton bush $U_{\min }$, we use the known range equations [19-28]:

$$
\begin{gathered}
R_{0}=\text { const, } D=\frac{12.4 K U_{a v} R_{O}}{U_{\min }} \\
Q_{v}=\text { const, } D=\frac{7 K \sqrt{Q_{o} U_{a v}}}{U_{\min }} \\
N_{v}=\text { const, } D=\frac{189 K \sqrt{N_{v}}}{U_{\min } \sqrt{U_{a v}}}
\end{gathered}
$$

The range of fan sprayers depends on the average axial velocity $U_{c p}$ of the airflow. To determine the average axial velocity of the airflow on the nozzle section when installing a pneumatic disc sprayer, consider the mass of the second volume of air passing through the outlet section of the nozzle:

$$
Q_{a v}=Q_{1}+Q_{2}
$$

where $Q_{1}=\pi U_{1} \gamma_{v}\left(R_{o}^{2}-R_{v}^{2}\right)$ is weight of the second volume of air flowing outside the area swept by the wind wheel, $\mathrm{kg} / \mathrm{ms}^{2} ; Q_{2}=\pi U_{1} \gamma_{v} R_{v}^{2}$ is weight of the second volume of air flowing through the area swept by the wind wheel, $\mathrm{kg} / \mathrm{m} \mathrm{s}^{2}$.

Substituting the value of $\mathrm{Q}_{1}$ and $\mathrm{Q}_{2}$ in the expression (25) and using the formula (21), we determine the average axial velocity of the airflow:

$$
U_{a v}=\frac{U_{0}\left(R_{o}^{2}-R_{v}^{2}\right)}{R_{o}^{2}-r_{k}^{2}}-\frac{R_{v}^{2}}{R_{o}^{2}} U_{o} \sqrt[3]{\xi}
$$

Based on the fact that for a serial sprayer $\mathrm{R}_{0}=0.2 \mathrm{~m}$ and at $r_{k \max }=0.096 \mathrm{~m}$, substituting the value $\mathrm{U}_{3}(20)$ in the formula (26), we find the average axial velocity of the air flow at the outlet section of the nozzle of the fan unit with a pneumatic disk sprayer:

$$
U_{a v}=U_{\mathrm{o}}\left[1-25 R_{v}^{2}(1-\sqrt[3]{\bar{\xi}})\right]
$$

Figure 6 shows the theoretical dependence of the mid-axis velocity $U_{a v}$ on the coefficients $\xi$ at $R_{v}=0.10 \ldots 0.15$ and $U_{\mathrm{o}}=$ const. 


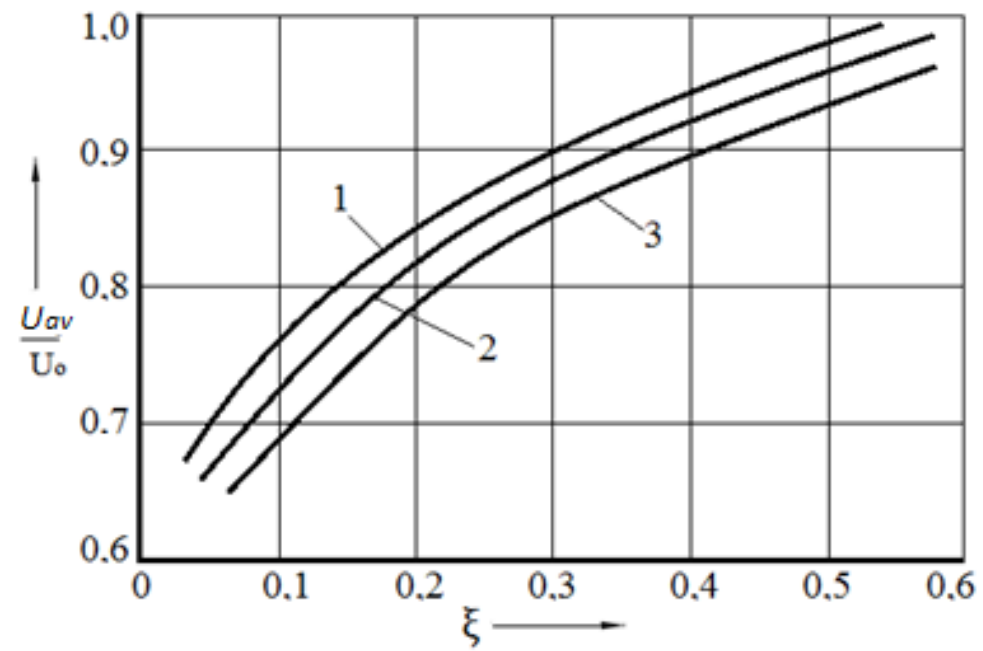

Fig. 6. The dependence of the average axial speed of a fan unit with a disk spray on the coefficient $\xi$ and the radius $R_{v}$, relative to $U_{0}$ :

$$
1-R_{v}=0.1 \mathrm{~m} ; 2-R_{v}=0.125 \mathrm{~m} ; 3-R_{v}=0.15 \mathrm{~m}
$$

Thus, by determining the value of $U_{C P}$ and substituting it into the equation (22), we obtain an expression for determining the range of a fan installation with a pneumatic disk sprayer:

$$
D=\frac{12.4 K\left[1-25 R_{0}^{2}(1-\sqrt[3]{\xi}) R_{o}\right.}{U_{\min }}
$$

It follows from expression (28) that the range of a fan installation with a pneumatic disk sprayer mainly depends on the coefficient $\xi$ of the energy use of the airflow and the radius $\mathrm{Rb}$ of the wind wheel. At the maximum value of these parameters, i.e. $\xi$ and $R_{b}$, the range $D$ of the fan unit will be maximum.

\section{Conclusions}

Smooth variation of the axial velocity air flow fan installations and prevent the transfer of the isothermal jet of the circular cross-section of the airflow into the annular, possibly with applications on disk atomizer additional fairing with the lateral expansion angle $\theta<$ $30^{\circ}$ and radius of the base of $r_{k \max }<0.096 \mathrm{~m}$. To reduce the influence of the pneumatic disk sprayer on the change in the axial air flow speeds and the range of the fan installation, it is necessary to use a wind wheel with the highest coefficient of use of the air flow energy $(\xi>0.40)$.

\section{References}

1. Aliev B.G. application of herbicides in the cotton-growing zone of Uzbekistan. Tashkent: Fan, 1971-212 p.

2. Balazh F. Increasing the efficiency of plant protection by new methods and machines // International agricultural. Journal. -№1.-(1984). -102. 
3. Bayramov K. Defoliation of cotton on different backgrounds of mineral nutrition // Cotton growing. No. 7. - -S.24-26. (1980).

4. Sokhta A.K., Madzhidov U.A. Technology and efficiency of low-volume and ultralow-volume spraying of cotton // Mechanization of cotton growing. -(1982). -No. 3. FROM. 14-15.

5. Veletsky I.N. Herbicide application technology. -L .: Agropromizdat, (1989).-175 p.

6. Veletsky I.N. Prospects for the development of mechanization // Plant protection. №1. -(1985). -WITH. 34-35

7. Geisbüller I.M. Chemical method - present and future // Plant protection. -1982. -№4. -S.40-41

8. Arifjanov, A., Juraev, S., Samiev, L., Ibragimova, Z., Babajanov, F. Determination of filtration strength and initial filtration gradient in soil constructions. (2020) Journal of Advanced Research in Dynamical and Control Systems, 12 (4 Special Issue), pp. 1860-1864. DOI: 10.5373/JARDCS/V12SP4/20201672

9. Arifjanov, A., Rakhimov, K., Abduraimova, D., Akmalov, S. Transportation of river sediments in cylindrical pipeline (2019) IOP Conference Series: Earth and Environmental Science, 403 (1). DOI: 10.1088/1755-1315/403/1/012154.

10. Korn G., Korn T. Handbook of mathematics for scientists and engineers. $-\mathrm{M}$.: Science. -1990. $-720 \mathrm{~s}$.

11. A. Lee, S. Allaniyazov, I. Khudaev, T. Usmonov, I. Gorlova. Modeling The Motion Of Alferia Seeds In The Sorting Device. International Jornal of Advanced and Technjljgy. -Vol. 29 No. 7 (2020). -P. 3431-3435.

12. Lee A., Usmonov T., Norov B. Seiling and cleaning of channels. (2020) IOP Conference Series: Materials Science and Engineering 883 (2020) 012062 IOP Publishing (doi: 10.1088 / 1757-899X / 883/1/012062)

13. Lee, A., Usmonov T., Norov B., Melikuziev, S. Advanced device for cleaning drain wells. (2020) IOP Conference Series: Materials Science and Engineering, 883 (1), No. 012181, DOI: 10.1088 / 1757-899X / 883/1/012181 Tashkent Institute of Irrigation and Agricultural Mechanization Engineers, Tashkent, Uzbekistan.

14. Lazarev G.S. Obtaining finely dispersed water and transporting it by air flow, p.210, (1952)

15. Study of the aerodynamic parameters of the working body of the cotton sprayer OBX28 / Report of GSKB on machines for cotton growing. p.89, (1982)

16. Martynov A.K. Experimental aerodynamics, p.345 Moscow, (1958)

17. Taliev V.N. Ventilation aerodynamics, p.297, Moscow, Stroyizdat, (1979)

18. Prokopenko S.F., Georgiev M.P. To the calculation of the main parameters of air jets of fan sprayers, Tractors and agricultural machines, № 2, pp. 7-11, (1968)

19. Arifjanov, A., Rakhimov, K., Abduraimova, D., Babaev, A., Melikuziyev, S. Hydrotransport of river sediments in hydroelelators. (2020) IOP Conference Series: Materials Science and Engineering, 869 (7). DOI: 10.1088/1757-899X/869/7/072003

20. Arifjanov A., Rakhimov Q., Samiev L., Abduraimova D., Apakhodjaeva T. Hydraulic friction coefficient at hydraulic mixing movement in pressure pipelines (2020) Journal of Advanced Research in Dynamical and Control Systems, 12 (7 Special Issue), pp. 1332-1336. DOI: 10.5373/JARDCS/V12SP7/20202233

21. Muratov, A., Muratov O., Melikuziyev S. Operational control of energy consumptions of reclamation machines, IOP Conference Series: Earth and Environmental Science, 614 (1), (2020) DOI: 10.1088/1755-1315/614/1/012042

22. Gushchin E.G. Investigation of the technological process of a low-volume cotton sprayer in order to optimize the design parameters of the jet-forming device of the fan sprayer / Dissertation. Dushanbe, p.204, (1976) 
23. B. Utepov. Justification of the basic parameters and operating modes of the pneumatic disc sprayer of the low-volume cotton sprayer, p. 18, (1993)

24. Rakhmonov S., Umurzakov U., Rakhmonov K., Bozarov I., Karamatov O. Land use and land cover change in Khorezm, Uzbekistan. E3S Web of Conferences, 227, 01002, (2021)

25. Umurzakov U., Mamatov F., Aldoshin N., Mirzaev B. Exploration of tillage technologies in the Republic of Uzbekistan, IOP Conference Series, Earth and Environmental Science, 614(1), 012168, (2020)

26. Umurzakov U., and Djuraev B. Prediction of prices for agricultural products through markov chain model, International Journal of Psychosocial Rehabilitation, 24(3), pp. 293-303, (2020)

27. Umurzakov U., Mirzaev B., Salahodjaev R., Isaeva A., and Tosheva S. Energy consumption and economic growth: Evidence from post-communist countries. International Journal of Energy Economics and Policy, 10(6), pp. 59-65, (2020)

28. Matyakubov B., Begmatov I., Raimova I. and Teplova G. Factors for the efficient use of water distribution facilities. IOP Conf. Ser. Mater. Sci. Eng. 883, 012025 (2020). 